
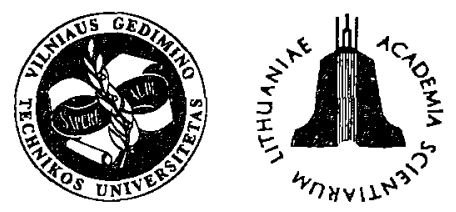

ISSN 1648-4142 TRANSPORT

http:/www.vtu.lt/english/editions

TRANSPORT-2002, Vol XVII, No 4, 143-146

\title{
THE IMPROVEMENT OF THE TECHNICAL EXPLOITATION OF AUTOMOBILES
}

\author{
Valentinas Mickūnaitis ${ }^{1}$, Saulius Nagurnas ${ }^{2}$ \\ Department of Automobile Transport, Vilnius Gediminas Technical University, \\ J. Basanavičiaus g. 28, LT-2009 Vilnius, Lithuania, Tel. (8-5) 2125551
}

Received 200204 25; accepted 20020617

\begin{abstract}
This article analyses the factors that considerably influence the efficiency of automobile technical exploitation. It has been noted that automobile technical exploitation is basically determined by the following factors: the system and organizational level of automobile technical maintenance and repairs; the level of service basis; qualification of the staff; the level of stock and supply; the structure and age of automotive fleet and conditions of exploitation.

This article presents the analysis of the first factor. The factor is significant enough and does not involve big investments.

A theoretical analysis of the system of automobile technical maintenance and repair has been carried out. According to the nature of automobile technical maintenance and repairs two strategies are possible: the planned - preventive and the mixed type. Applying the first strategy the exact number of operations is being planned ahead, but the amount of work remains unknown. According to the second strategy the technical condition of an automobile has to be checked before starting technical maintenance and repair and only then the exact number of operations can be defined. The second strategy makes it possible to save spare parts, materials and time. This strategy, however, can be applied to the automobiles that are in good technical condition.

The analysis of automobile technical maintenance and repair organization has shown that in order to improve the efficiency of automobile technical maintenance and repair the laws of mass service theory should be applied.
\end{abstract}

Keywords: efficiency of automobile exploitation, system of automobile technical maintenance and repairs, strategy of automobile repairs.

\section{Introduction}

Now there is no unified strategy of the technical exploitation of automobiles because of its dependence on many factors (indications of automobile quality, conditions of exploitation a.o.). Therefore it is important to establish criteria which would improve, if taken as foundation, the efficiency of technical service and repair system.

In the optimization of the production process of the technical exploitation of automobiles the analysis of the main factors having influence on the efficiency of the process is of primary importance.

The main goals of the technical exploitation of automobiles are [1-5]: the increase of the workability of the automotive fleet; the increase of the labour productivity of the working staff; the reduction of the expenditure for technical service and repair of automobiles; the protection of personnel and environment from a harmful influence of automobiles in bad working order.

The level of workability of an automotive fleet is being characterized by the following indications: readiness

\footnotetext{
'E-mail: vmick@mail.lt

2E-mail: saunag@ti.vtu.It
}

ratio, time-to-failure, probabilities of reliable work en route, total idle standing for maintenance and repair.

The efficiency of technical exploitation is determined by the following factors [6-8]: the system and level of organization of automobile technical maintenance and repairs - 19\%; the level of the industrial and technical basis $-18 \%$; the qualification of the staff - $16 \%$; the level of supply and reservation $-9 \%$; the structure and lifetime of the automotive fleet $-25 \%$; working conditions $-13 \%$.

This article presents the analysis of the influence of the first factor on the industrial process of automobile technical exploitation because it is important and does not involve great expense. There is also a theoretical possibility of selection the strategy of automobile technical maintenance and repair.

Some factors connected with the organization of automobile technical maintenance and repair having influence on the volume of work (e.g. indications of automobile reliability, parameters of failures flow a.o.) are also being examined. On the ground of the manifestation of the regularity of these factors the optimization of the working process and of the industrial capacity is based. The theory of mass service is applicable for this purpose because of its good descriptive ability for the manifestation of failure flows [8]. 


\section{Analysis of the System of Automobile Technical Main- tenance and Repair}

The system of automobile technical maintenance and repair sets the rational strategy of supporting automobile workability and its restoration. The strategy can be divided into the following different parts:

1) normative basis of work, connected with the technical maintenance and repair;

2) application of advanced technologies in the technical maintenance and repair;

3) improvement of organization and management;

4) improvement of account making;

5) flexible adaptation of the system of technical maintenance and repair to the variable situation (automobile structure, working conditions a.o.).

Taking into account the character of automobile technical maintenance and repair there are two strategies possible: the planned-preventive and the mixed one.

According to the first strategy the accurate number of operations is known beforehand, but the volume of work is unknown. According to the second strategy before the beginning of the technical maintenance or repair the technical state of a car is examined and only after that the number of necessary operations is determined. In such case both the number of operations and the volume of work are random variables. If the second strategy is applied there is a possibility of saving spare parts, materials and time. But this strategy can be applied only to automobiles with good indications of infallibility and reparability. For the evaluation of automobile reparability some special indication is used - total standing idle $t$ for maintenance and repair.

The total working hours of technical maintenance and repair according to the first strategy $t=t_{\Sigma} \cdot N$, according to the second one $-t=t_{\Sigma} \cdot n$. They can be calculated according to the expressions [9]:

$$
\begin{aligned}
& t_{\Sigma} \cdot N=\sum_{1}^{N} t \sum i \\
& t_{\Sigma} \cdot n=\sum_{1}^{n} t \sum_{i}+\sum_{1}^{N} t \sum i k,
\end{aligned}
$$

here $N$ - the number of automobile parts to be adjusted, repaired or changed in accordance with prescriptions in the technical documentation; $n$ - the number of automobile parts to be adjusted, repaired or changed after the evaluation of their technical state; ${ }^{t} \sum_{i}$ - the total working hours of technical maintenance and repair of the $i$ - th part; $t \sum_{i k}$ - the total working hours for control of the $i-$
th part.

The first term of the right side of the equation (2) can be expressed as follows:

$$
\sum_{l}^{n} t \sum_{i}=\sum_{l}^{N} F_{i} \cdot t \sum_{i}
$$

here $F_{i}$ - the probability of necessity of change or repair of the $i$ - th part after the control was carried out.

Putting in the expression (3) into the expression (2) results as below:

$$
t_{\Sigma} \cdot n=\sum_{1}^{N}\left(F_{i} \cdot t_{\sum i}+t_{\Sigma i k}\right) .
$$

The variables in these expressions are of random type therefore for choosing the strategy of technical maintenance and repair the integral distribution functions $F_{1} \cdot t_{\Sigma} \cdot N, F_{2} \cdot t_{\Sigma} \cdot n F_{3} \cdot t_{\sum i k}, F(n)$ must be found for the variables $t_{\Sigma} \cdot N, t_{\Sigma} \cdot n, t_{\sum i k}$ and $n$.

Having them we can calculate the expectation values $M\left[t_{\Sigma} \cdot N\right], M\left[t_{\Sigma} \cdot n\right], M\left[t_{\sum i k}\right\rfloor$ and $M[n]$ for the random variables.

The expectations of the total working hours of automobile technical maintenance and repair work can be calculated according to such expressions:

$$
\begin{aligned}
& M\left[t_{\Sigma} \cdot N\right]=N \cdot \bar{t} \Sigma, \\
& M\left[t_{\Sigma} \cdot n\right]=M[n] \cdot \bar{t}^{-} \sum+N \cdot{ }^{-} \sum_{\Sigma k}= \\
& N \cdot F_{m} \cdot \bar{t} \Sigma+N \cdot t_{k},
\end{aligned}
$$

here ${ }^{t} \sum$ and ${ }^{t} \sum k$ are the average duration of the technical maintenance and repairs of an automobile part; $M[n]-$ the expectation of the number of work of technical maintenance and repair which are carried out after the control. It can be calculated by the formula:

$$
M[n]=N \cdot F_{m},
$$

here $\vec{F}_{m}$ - average probability of automobile parts failures.

There are three possible cases of analysis in strategy selection:

$$
\begin{aligned}
& \text { 1) } M\left[t_{\Sigma} \cdot N\right]<M\left[t_{\Sigma} \cdot n\right], \bar{t}_{\Sigma}<\bar{F}_{m} \cdot \bar{t}_{\Sigma}+\bar{t}_{\Sigma k}, \\
& \text { 2) } M\left[t_{\Sigma} \cdot N\right]>M\left[t_{\Sigma} \cdot n\right],{ }^{t} \sum>\bar{F}_{m} \cdot{ }^{t} \Sigma+{ }^{t} \sum_{\Sigma},
\end{aligned}
$$

3) $M\left[t_{\Sigma} \cdot N\right]=M\left[t_{\Sigma} \cdot n\right],{ }^{t} \Sigma=F_{m} \cdot{ }^{i} \Sigma+t{ }^{2} k$,

If the first condition is satisfied, the use of the first strategy is economically useful. If the second condition is satisfied, the use of the second strategy is rational. If the third condition is satisfied, the analysis of $F \cdot\left(M\left[t_{\Sigma} \cdot N\right]\right)$ and $F \cdot\left(M\left[t_{\Sigma} \cdot n\right]\right)$, is necessary, i.e. evaluation of expectations corresponding to values of the integral distribution functions for the reparability indication chosen is necessary. When $F \cdot\left(M\left[t_{\Sigma} \cdot N\right]\right)>F \cdot\left(M\left[t_{\Sigma} \cdot n\right]\right)$, the use of the second strategy is economically useful. 


\section{The Organization of Work of Automobile Technical Maintenance and Repair}

With the purpose of organizational improvement of automobile technical maintenance and repair it is necessary to know the character of such work, its volume at some time and also the factors having influence on the volume. There is no possibility of rational industrial organization (evaluation of manpower, industrial basis, need of spare parts and raw materials) of production process.

The volume of technical maintenance and repair work mostly depends on the technical status of the automotive fleet and it can be evaluated by reliability indications. The connection between the reliability indications and the total failure flow can be described by some cubic equation [8].

The main indications of the third level dependence are: the average amount of work done (run) before failure, the average run between failures, the coefficient of resource restoration, the main function of the failure flow and the parameter of failure flow.

The average amount of work done before failure:

$$
\begin{aligned}
& \bar{X}_{k}=\bar{X}_{1}+\bar{X}_{12}+\bar{X}_{23}+\ldots+\bar{X}_{k-1, k}= \\
& \bar{X}_{1}+\sum_{k=2}^{k} \dddot{X}_{k-1, k},
\end{aligned}
$$

here $\bar{X}_{1}-$ the average run before first failure; $\bar{X}_{12}-$ the average run between failures 1 and 2 etc.

The average run between failures for the number of $n$ automobiles:

$$
\bar{X}_{12}=\frac{\sum_{i=1}^{n} \bar{X}_{12}}{n},
$$

or

$$
\bar{X}_{k-1, k}=\frac{\sum_{k=1}^{n} X_{k-1, k}}{n}
$$

The coefficient of resource restoration:

$$
\eta_{1}=\frac{\bar{X}_{12}}{\bar{X}_{1}}
$$

which characterizes the repair quality between failures 1 and 2 or after $k$ failures:

$$
\eta_{k}=\frac{X_{k, k+1}}{X_{1}}
$$

This indication depends on the repair quality (spare parts, technology, equipment, qualification of the staff etc.).

The main function of the failure flow (number of failures to $x$ run):

$$
\Omega_{\left(x_{1}\right)}=F_{1\left(x_{1}\right)}
$$

here $F_{1}$ - the probability of the first failure.

In the general case (when $x_{n}$ ):

$$
\Omega_{\left(x_{n}\right)}=\sum_{k=1}^{k=n} F_{k\left(x_{n}\right)} .
$$

The parameter of the failure flow:

$$
\omega_{(x)}=\frac{d \Omega(x)}{d x}=\sum_{k=1}^{k=n} f_{k(x)},
$$

here $f_{k(x)}$ - the probability density of the $k$ - th failure appearance.

The parameter $\omega_{(x)}$ of the failure flow can be evaluated on the base of statistical data:

$$
\omega_{(x)}=\frac{m\left(x_{1} \cdot x_{2}\right)}{n\left(x_{2}-x_{1}\right)}=\frac{\Omega_{\left(x_{2}\right)}-\Omega_{\left(x_{1}\right)}}{x_{2}-x_{1}},
$$

here $m\left(x_{1} \cdot x_{2}\right)$ - the number of failures of $n$ automobiles between runs $x_{1}$ and $x_{2} ; \Omega_{\left(x_{1}\right)}, \Omega_{\left(x_{2}\right)}$ - the main functions of the failure flow for runs $x_{1}$ and $x_{2}$.

The probability of some number of failures of the failure flow during the given time interval is characterized by the Poisson distribution $[8,9]$ :

$$
P_{k(t)}=\frac{(\omega \cdot t)^{k}}{k !} \cdot \exp (-\omega \cdot t),
$$

here $k=0,1,2, \ldots$ - the number of failures, which appear in the time interval $t ; \omega$-the parameter of the failure flow.

In the industrial enterprises the failure number is usually registered for a shift, or twenty-four hours, or a week etc. It means, that $t=1$, and when $\omega \cdot t=\Omega_{0}=\bar{a}$ - the average number of failures during time $t$.

Thus:

$$
P_{k(t)}=\frac{\bar{a}^{k}}{k !} \cdot \exp (-a) \text {. }
$$

Automobiles are repaired in the area for technical service and repair of any motor transport plant. The industrial capacity of this area is used with a certain probability, therefore for the capacity optimization the proper application of mass service theory is purposeful.

Using the formula (21) the calculation of probability $P_{k(t)}$ of automobile appearance to the service and repair area for repair is possible if the $a$ parameter is known.

Knowing the probability we can get more accurate evaluation of the volume of work and the need of manpower and material resources.

\section{Conclusions}

1. With the purpose of the improvement of the process of automobile technical exploitation the choice of a 
proper strategy of technical service and repair is of significant importance. The choice of such strategy depends on the automobile incorruptibility indications -the probability of failure and reparability. The decrease of these indications shows that the second strategy of automobile technical service and repair is economically more useful. It enables to increase the automobile reliability with less time and material losses.

2. It is purposeful to optimize the industrial capacity of the service and repair area by the proper application of mass service theory, which takes into account not only failure flows, but also the repair duration.

\section{References}

1. Profiting from quality in the service area. Quality Progress, Vol 32, No 5, 1999, p 81-84.

2. Elmuti, Dean S. Kathawala, Yunus. Small service firms face implementation challenges. Quality progress, Vol 32, No 4, 1999, p 67-75.

3. Andaleeb S. S., Basu A. K. Do warranties influence percep- tions of service quality; A study of the automobile repair and service industry. Journal of Retailing and Consumer Services, Vol 5, No 4, 1998, p 87-91.

4. Council Directive 92/59/EEC of 29 June 1992 on general product safety.

5. Efficient transport for Europe. Policies for intemalisation of extemal corts. In: European conference of Ministers of transport. Paris, 1998. $261 \mathrm{p}$.

6. Sanseverino, Marialuisa, Cascio, Fulvio. Model-based diagnosis for automotive repair. IEEE Intelligent Systems \& Their Applications, Vol 12, No 6, 1997, p 33-37.

7. EN ISO 9001: 1994, Quality systems. Model for quality assurance in design, development, production, installation and servicing.

8. Kuznetsov E. S. The management of the technical exploitation of automobiles (Управление технической эксплуатанией автомобилей). Moscow: Transport, 1990. 272 p (in Russian).

9. Baykhelt F, Franken P. The reliability and the technical service. A mathematical approach (Надежность и техническое обслуживание). Moscow: Radio i sviaz, 1988. 392 p (in Russian). 